УДК 611.12/.4 + 616.126.4-007.271] - 053.2

DOI: $10.26435 /$ UC.V0I3(36).540

\author{
Л.В Васильева, В.А. Васильев, К.А. Мурейси
}

ГОО ВПО «Донецкий национальный медицинский университет имени М. Горького», Донецк

\title{
АНАТОМИЧЕСКИЕ ОСОБЕННОСТИ КРОВОСНАБЖЕНИЯ СЕРДЕЦ ДЕТЕЙ ПРИ СОЧЕТАНИИ ОТКРЫТОГО АТРИОВЕНТРИКУЛЯРНОГО КАНАЛА СО СТЕНОЗОМ И АТРЕЗИЕЙ УСТЬЯ ЛЕГОЧНОГО СТВОЛА
}

Врожденные пороки сердца (ВПС) - одни из наиболее распространенных пороков развития у детей. По данным разных авторов, показатели распространенности ВПС в мире у детей значительно варьируют и составляют от 4 до 50 случаев на 1000 живорожденных [1-3]. В России ежегодно рождаются около 22 тысяч детей с врожденным пороком сердца [4], а в мире - около 1,5 млн детей $[3,5]$. Эти аномалии являются ведущей причиной смерти у детей первого года жизни $[6,7]$. По статистике 36\% новорожденных, у которых есть порок сердца, умирают в течение первого месяца жизни, еще 35,5\% - в течение последующих 11 месяцев. Таким образом, фактически из 100 детей, которые родились с ВПС, в течение первого года почти $72 \%$ нуждаются в операции [8].

В числе ВПС встречается один из сложных пороков - открытый атриовентрикулярный канал, частота которого составляет 4,21 на 10000 человек [3]. Эта аномалия может сочетаться с пороками конотрункуса (аномалии развития артериальных конусов, аорты, легочного ствола). К порокам конотрункуса относится атрезия легочной артерии, которая представляет собой врожденное отсутствие прямого сообщения между правым желудочком (ПЖ) и системой легочной артерии (ЛА). Это довольно редкий ВПС, который отмечается в 2-3\% случаев от всех ВПС [9] или в 0,86 случаев на 10000 населения [3]. Стеноз устья легочной артерии встречается в 3,87 на 10000 населения [3]. Эти пороки сопровождаются развитием критических состояний в 98,7\% [10].

Тот факт, что такие сочетания встречаются редко, а также разнообразие анатомических форм затрудняет изучение порока и не позволяет накопить достаточный опыт для диагностики и хирургической коррекции порока. Поэтому, роль морфологов состоит в предоставлении детальных данных при сложных сердечных аномалиях.

\section{ЦЕЛЬРАБОТЫ}

Выявить особенности кровоснабжения стенок камер сердца при сочетании открытого атриовентрикулярного канала со стенозом и атрезией устья легочного ствола.

\section{МАТЕРИАЛ И МЕТОДЫ}

Авторы исследовали 3 препарата сердечнолегочных комплексов детей в возрасте: 1 сутки, 10 дней и 8 мес., умерших в связи с наличием врожденного порока сердца открытого атриовентрикулярного канала, сочетающегося со стенозом или атрезией устья легочного ствола. Использованы методы анатомического препарирования сосудов. Методом описательной анатомии исследовали топографию устьев венечных артерий и магистральных стволов, тип ветвления артериальных сосудов, угол отхождения ветвей.

\section{РЕЗУЛЬТАТЫ И ОБСУЖДЕНИЕ}

Во всех случаях имелись нарушения внутрисердечной гемодинамики. Так, у ребенка прожившего 1 сутки после рождения, полная форма открытого атриовентрикулярного канала сочеталась с атрезией устья легочного ствола, а кровоток в малый круг кровообращения осуществлялся через артериальные сосуды, один из которых отходил сзади от плечеголовного ствола и соединялся с правой легочной артерией, в то время как второй сосуд ответвлялся от нижней стенки дуги аорты и присоединялся к левой легочной артерии (рис. 1.).

Во втором наблюдении у мальчика возрастом 10 дней полная форма порока имела сочетание с инфундибулярным стенозом устья легочного ствола, который со своими ветвями был

(с Л.В Васильева, В.А. Васильев, К.А. Мурейси, 2020 (c) Университетская Клиника, 2020 


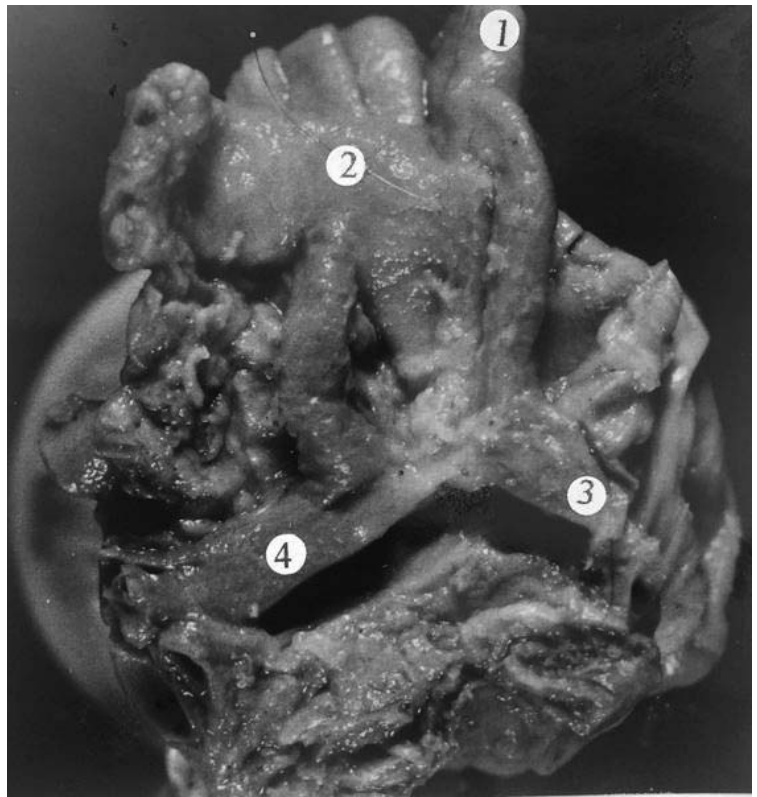

Рис. 1. Препарат сердца с открытым атриовентрикулярным каналом в сочетании с атрезией устья легочного ствола ребенка возрастом 1 сутки. 1 - плечеголовной ствол; 2 - дуга аорты; 3 - правая легочная артерия; 4 - левая легочная артерия.

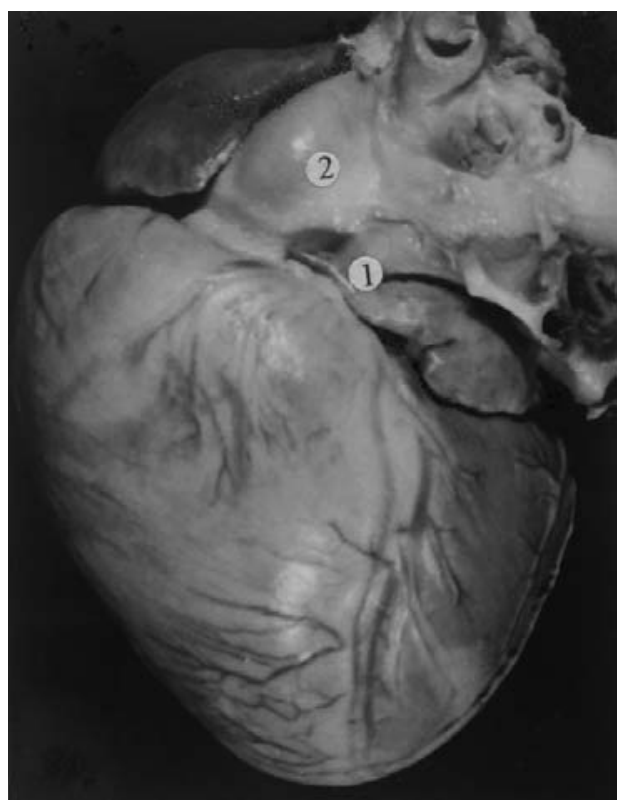

Рис. 2. Препарат сердца с открытым атриовентрикулярным каналом в сочетании со стенозом устья легочного ствола ребенка возрастом 10 дней. 1 - гипоплазированный легочный ствол; 2 - аорта.

гипоплазирован на фоне декстрапозиции аорты (рис. 2.).

В последнем случае у ребенка с болезнью Дауна возрастом 8 мес. 24 дня имело место сочетание полной формы открытого атриовентрикулярного канала с атрезией устья легочного ствола, при котором кровь в малый круг крово-

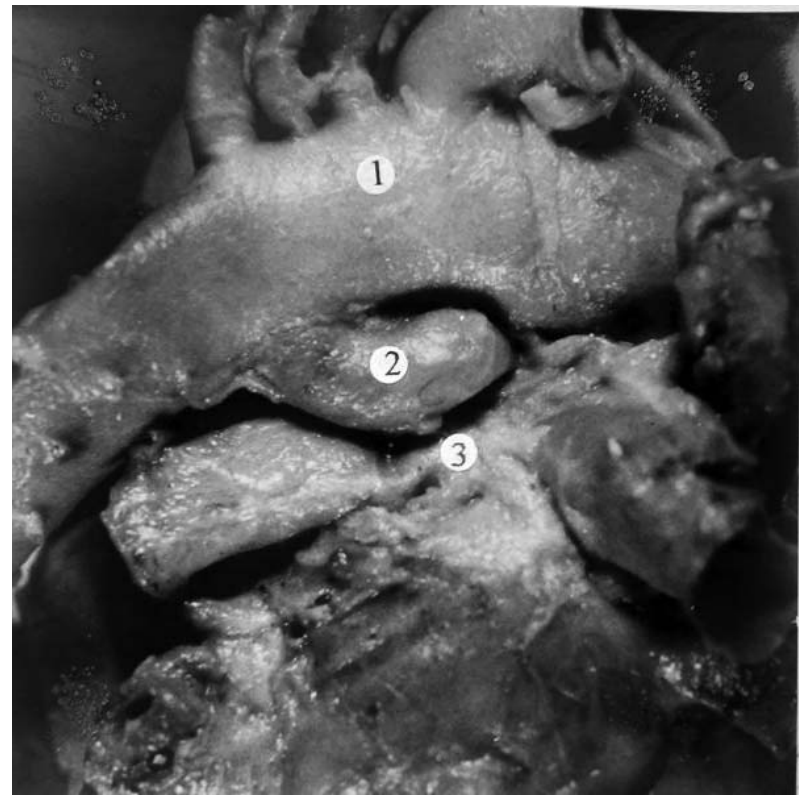

Рис. 3. Препарат сердца с открытым атриовентрикулярным каналом в сочетании с атрезией устья легочного ствола ребенка возрастом 8 мес. 24 дня. 1 дуга аорты; 2 - артериальный проток; 3 - гипоплазированный легочный ствол.

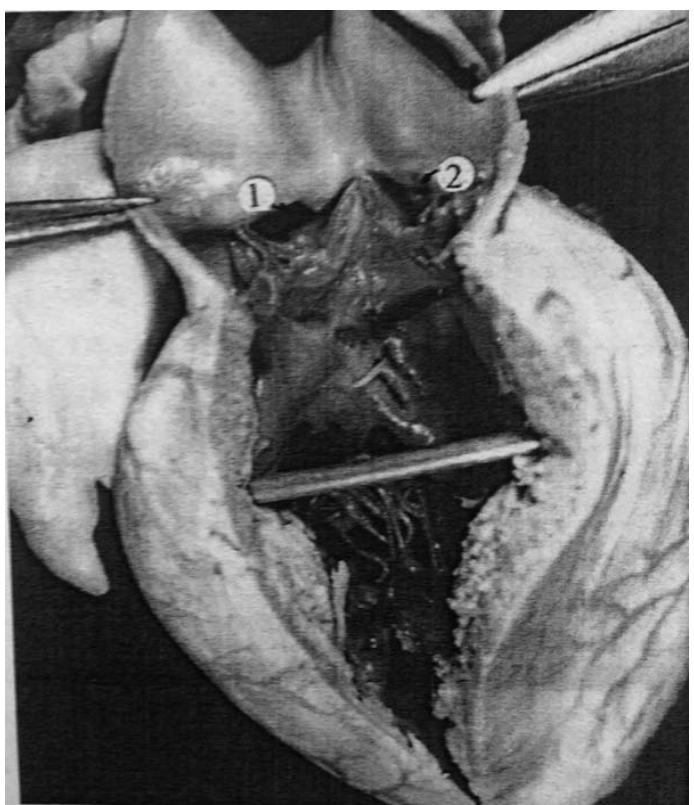

Рис. 4. Препарат сердца с открытым атриовентрикулярным каналом в сочетании с атрезией устья легочного ствола. 1 - устье левой венечной артерии; 2 - устье правой венечной артерии в заднем аортальном синусе.

обращения поступала через открытый артериальный проток. Он соединял нижний отдел дуги аорты с бифуркацией гипоплазированного легочного ствола (рис. 3.).

Во всех приведенных случаях кровоснабжение сердца осуществлялось правой и левой ве- 
нечными артериями, устья которых располагались в одноименных аортальных синусах на уровне свободного края полулунных заслонок. Лишь у восьмимесячного ребенка устье левой венечной артерии находилось на 3 мм выше аортального синуса, а у мальчика, прожившего одни сутки, устье правой венечной артерии было обнаружено в заднем синусе аорты (рис. 4.). В этом случае ствол левой венечной артерии имел длину 2 мм, после чего он разветвлялся на переднюю межжелудочковую, диагональную и огибающую артерии. Передняя межжелудочковая ветвь проходила в одноименной борозде, ветвилась по магистральному типу и на своем пути кровоснабжала передние стенки желудочков и межжелудочковую перегородку. Затем она огибала сердечную вырезку и своими конечными артериальными сосудами заканчивалась на задних стенках желудочковых камер на уровне их средних отделов.

Диагональная артерия давала свои ветви передней стенке левого желудочка и заканчивалась на верхушке сердца. Огибающая ветвь левой венечной артерии следовала по венечной борозде и на своем пути кровоснабжала стенки левых предсердия и желудочка. На диафрагмальной поверхности органа она перед задней межжелудочковой бороздой поворачивала книзу и заканчивалась в среднем отделе задней стенки левого желудочка.

Правая венечная артерия в данном случае начиналась от заднего аортального синуса и

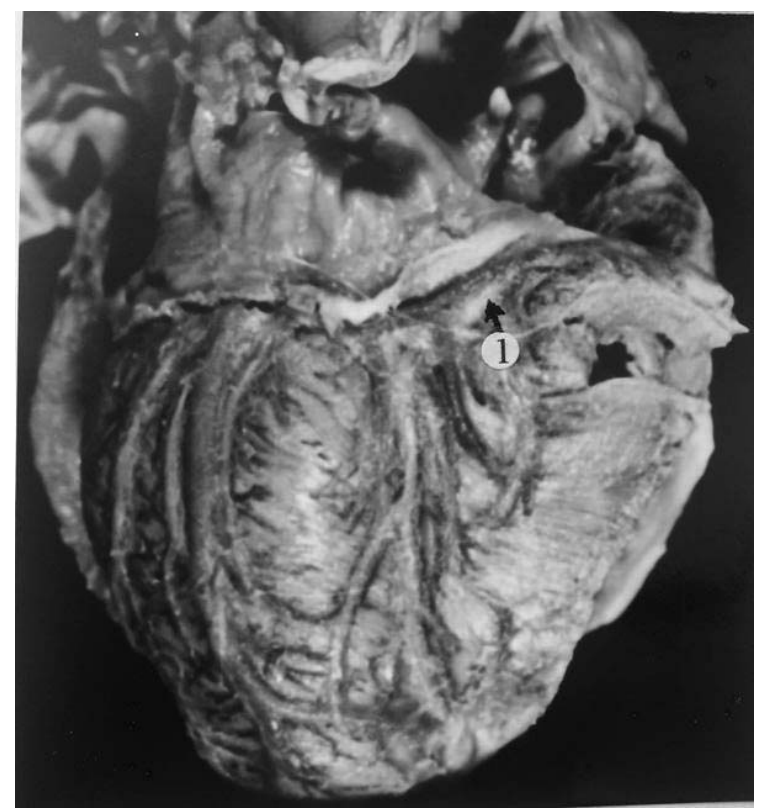

Рис. 5. Препарат сердца с открытым атриовентрикулярным каналом в сочетании со стенозом устья легочного ствола. 1 - правая венечная артерия. Вид диафрагмальной поверхности сердца. своим основным стволом направлялась к венечной борозде, в которой первой ответвлялась артерия конуса. Давая мелкие артериальные ветви к стенкам правого предсердия, правая венечная артерия на уровне правого края сердца осуществляла ответвление правой краевой, а на диафрагмальной поверхности - задней правожелудочковой ветвей крупных калибров, кровоснабжающих на своем пути стенки правого желудочка. Затем она продолжалась в задней межжелудочковой борозде, являясь задней межжелудочковой ветвью, и заканчивалась у верхушки сердца.

Во втором наблюдении у десятидневного ребенка со стенозом устья легочного ствола присутствовала правовенечная форма кровоснабжения сердца. При этом левая венечная артерия своей передней межжелудочковой ветвью кровоснабжала передние стенки желудочков и межжелудочковую перегородку, а ее огибающая ветвь заканчивалась на уровне левого края сердца. Правая венечная артерия, следуя по венечной борозде, ветвилась по магистральному типу, кровоснабжая стенки правых предсердия и желудочка, а после ответвления задней межжелудочковой артерии, она переходила на заднюю стенку левого желудочка и двумя крупными ветвями осуществляла его кровоснабжение (рис. 5.).

У восьмимесячного ребенка с болезнью Дауна преобладал бассейн левой венечной артерии и при этом передняя межжелудочковая ветвь,

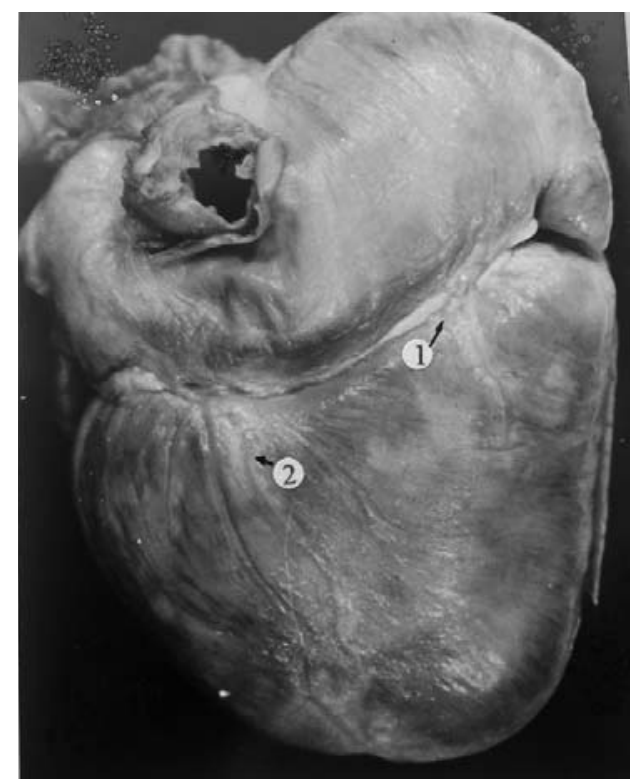

Рис. 6. Препарат сердца с открытым атриовентрикулярным каналом в сочетании с атрезией устья легочного ствола ребенка возрастом 8 мес. 24 дня. 1 правая венечная артерия. 2 - задняя межжелудочковая ветвь. Вид диафрагмальной поверхности сердца. 
отдавая ветви к передним стенкам желудочков и межжелудочковой перегородке, огибала сердечную вырезку и конечными артериальными сосудами достигала средних отделов задних стенок желудочковых камер. Однако правая венечная артерия ветвилась по магистральному типу, в то время как отходящие от нее крупные ветви имели рассыпной тип ветвления. Достигая задней межжелудочковой борозды, она ответвляла заднюю межжелудочковую артерию, которая ложилась в одноименную борозду, а сама затем следовала параллельно борозде по задней стен- ке левого желудочка. Рядом с ней находились ветви огибающей артерии (рис. 6.).

\section{В Ы В О Д b}

Кровоснабжение сердца при сочетании открытого атриовентрикулярного канала со стенозом и атрезией устья легочного ствола имеет свои особенности. Так, при атрезии устья легочного ствола преобладала левовенечная форма кровоснабжения сердца, а при стенозе его устья установлена правовенечная форма.

\section{Л.В Васильева, В.А. Васильев, К.А. Мурейси}

ГОО ВПО «Донецкий национальный медицинский университет имени М. Горького», Донецк

\section{АНАТОМИЧЕСКИЕ ОСОБЕННОСТИ КРОВОСНАБЖЕНИЯ СЕРДЕЦ ДЕТЕЙ ПРИ СОЧЕТАНИИ ОТКРЫТОГО АТРИОВЕНТРИКУЛЯРНОГО КАНАЛА СО СТЕНОЗОМ И АТРЕЗИЕЙ УСТЬЯ ЛЕГОЧНОГО СТВОЛА}

Авторы описали на 3 препаратах сердечнолегочных комплексов детей, умерших в связи с наличием врожденного порока сердца открытого атриовентрикулярного канала, сочетающегося со стенозом или атрезией устья легочного ствола особенности кровоснабжения стенок органов. Использованы методы препарирования и описательной анатомии. В одном случае, у ребенка прожившего 1 сутки после рождения, при сочетании полной формы открытого атриовентрикулярного канала с атрезией устья легочного ствола, кровоток в малый круг кровообращения осуществлялся через артериальные сосуды, один из которых отходил сзади от плечеголовного ствола и соединялся с правой легочной артерией, в то время как второй сосуд ответвлялся от нижней стенки дуги аорты и присоединялся к левой легочной артерии. Во втором наблюдении у мальчика возрастом 10 дней полная форма порока имела сочетание с инфундибулярным стенозом устья легочного ствола, кото- рый со своими ветвями был гипоплазирован на фоне декстрапозиции аорты. В последнем случае у ребенка с болезнью Дауна возрастом 8 мес. 24 дня имело место сочетание полной формы открытого атриовентрикулярного канала с атрезией устья легочного ствола, при котором кровь в малый круг кровообращения поступала через открытый артериальный проток. Он соединял нижний отдел дуги аорты с бифуркацией гипоплазированного легочного ствола.

Особенности ветвления и расположения ветвей правой и левой венечных артерий на стенках камер показали, что при атрезии устья легочного ствола преобладала левовенечная форма кровоснабжения сердца, а при стенозе его устья установлена правовенечная форма.

Ключевые слова: врожденный порок сердца, открытый атриовентрикулярный канал, стеноз устья легочного ствола, атрезия устья легочного ствола, венечные артерии.

\section{L.V. Vasil'eva, V.A. Vasil'ev, K.A. Mureisi}

SEI HPE «M. Gorky Donetsk National Medical University», Donetsk

\section{ANATOMICAL PECULIARITIES OF BLOOD SUPPLY TO THE HEARTS IN THE COMBINATION OF COMPLETE ATRIOVENTRICULAR CANAL DEFECT AND PULMONARY STENOSIS OR PULMONARY ATRESIA}

The authors described anatomical peculiarities of blood supply to the heart on 3 preparations of cardiopulmonary complexes of children who died due to congenital heart disease - the combination of complete atrioventricular canal defect and pulmonary stenosis or pulmonary atresia. In one case, in a child who lived 1 day after birth, complete atrioventricular canal defect was combined with pulmonary atresia, blood flow into the pulmonary circulation was carried out through arterial vessels, one of which departed from the back of the brachiocephalic trunk and connected to the right pulmonary artery, while the second vessel branched off from the lower wall of the aortic arch and attached to the left pulmonary artery.
In the second case, in a 10-day-old boy, complete atrioventricular canal defect was combined with pulmonary infundibular stenosis, which with its branches was hypoplastic against the background of aortic dextraposition.In the latter case, a child with Down's disease aged 8 months and 24 days, there was a combination of complete atrioventricular canal defect with pulmonary atresia, in which blood entered the pulmonary circulation through the open arterial duct. He connected the lower section of the aortic arch with bifurcation of the hypoplastic pulmonary trunk. Features of branching and the location of the branches of the right and left coronary arteries on the walls showed that in pulmonary atresia the left-coronary form of blood 
supply to the heart prevailed, and in pulmonary stenosis - a right-coronary form was established.
Key words: congenital heart disease, atrioventricular canal defect, pulmonary stenosis, pulmonary atresia, coronary arteries.

\section{ЛИТЕРАТУРА}

1. Hoffman J.I., Kaplan S., Liberthson R.R. Prevalence of congenital heart disease. Am Heart J. 2004;147 (3): 425-439. doi: 10.1016/ j.ahj.2003.05.003.

2. Becker S., Al Halees Z. First-cousin matings and congenital heart disease in Saudi Arabia. Community Genet. 1999; 2 (2-3): 69-73. DOI: 10.1159/000016189.

3. Саперова Е.В., Вахлова И.В. Врожденные пороки сердца у детей: распространенность, факторы риска, смертность. Вопросы современной педиатрии. 2017; 16 (2): 126-133. DOI: $10.15690 /$ vsp.v16i2.1713

4. Гончарь М.А. Современные подходы к диагностике врожденных пороков сердца. Здоров’я України. 2016; $36(1): 58$.

5. Кардиология детского возраста. Под ред. Царегородцева А.Д., Белозерова Ю.М., Брегель Л.В. М.: ГЭОТАРМедиа; 2014. 784

6. Зиньковский М.Ф. Врожденные пороки сердца. Под ред. А.Ф. Возианова. К.: Книга-плюс; 2010. 1200.

7. cdc.gov [Internet]. Centers for Disease Control and Prevention, National Center for Health Statistics. Mortality multiple cause microdata files, 2013: public-use data file and documentation: NHLBI

8. Фальковский Г.Э., Крупянко С.М. Сердце ребенка: Книга для родителей о врожденных пороках сердца. М.: Никея; 2011. 232.

9. Атрезия легочной артерии с дефектом межжелудочковой перегородки: Клинические рекомендации. 2016 URL: https://racvs.ru/clinic/files/2016/atresia-pulmonary-artery.pdf

10. Петренко Ю.В., Ляпунова А.А, Федосеева Т.А., Мызникова И.В. Диагностика и тактика ведения врожденных пороков сердца в неонатальном периоде: Клинические рекомендации. 2016; 31.

\section{REFERENCES}

1. Hoffman J.I., Kaplan S., Liberthson R.R. Prevalence of congenital heart disease. Am Heart J. 2004;147 (3): 425-439. DOI: 10.1016/ j.ahj.2003.05.003.

2. Becker S., Al Halees Z. First-cousin matings and congenital heart disease in Saudi Arabia. Community Genet. 1999; 2 (2-3): 69-73. DOI: 10.1159/000016189.

3. Saperova E.V., Vakhlova I.V. Vrozhdennye poroki serdtsa u detei: rasprostranennost', faktory riska, smertnost'. Voprosy sovremennoi pediatrii. 2017; 16 (2): 126-133 (in Russian). DOI: 10.15690/vsp.v16i2.1713

4. Gonchar' M.A. Sovremennye podkhody k diagnostike vrozhdennykh porokov serdtsa. Zdorov'ya Ukraïni. 2016; 36 (1): 58 (in Russian).

5. Kardiologiya detskogo vozrasta. Pod red. Tsaregorodtseva A.D., Belozerova Yu.M., Bregel' L.V. M.: GEOTAR-Media; 2014. 784 (in Russian).

6. Zin'kovskii M.F. Vrozhdennye poroki serdtsa. Pod red. A.F. Vozianova. K.: Kniga-plyus; 2010. 1200 (in Russian).

7. cdc.gov [Internet]. Centers for Disease Control and Prevention, National Center for Health Statistics. Mortality multiple cause microdata files, 2013: public-use data file and documentation: NHLBI

8. Fal'kovskii G.E., Krupyanko S.M. Serdtse rebenka: Kniga dlya roditelei o vrozhdennykh porokakh serdtsa. M.: Nikeya; 2011. 232 (in Russian).

9. Atreziya legochnoi arterii s defektom mezhzheludochkovoi peregorodki: Klinicheskie rekomendatsii. 2016 (in Russian). URL: https://racvs.ru/clinic/files/2016/atresiapulmonary-artery.pdf

10. Petrenko Yu.V., Lyapunova A.A, Fedoseeva T.A., Myznikova I.V. Diagnostika i taktika vedeniya vrozhdennykh porokov serdtsa v neonatal'nom periode: Klinicheskie rekomendatsii. 2016; 31 (in Russian). 